\title{
MATHEMATICAL DETERMINATION OF THERMAL LOAD FOR FLUIDISED BED FURNACES USING SAWDUST
}

NICOLAE ANTONESCU, Professor assistant, PhD, Technical University of Civil Engineering, Faculty of Building Services, e-mail: nicuant@yahoo.com

PAUL-DAN STANESCU, Professor, PhD, Technical University of Civil Engineering, Faculty of Building Services, e-mail: pauldan.stanescu@yahoo.com

\begin{abstract}
For technical applications, a physical model capable of predicting the particle evolution in the burning process along its trajectory through the furnace is very useful. There are two major demands: all the thermo-dynamic processes that describe the particle burning process must be accounted and the model must be written in such equation terms to allow the intervention for parameter settings and particle definition. The computations were performed for the following parameters: furnace average temperature between 700 and $1200{ }^{\circ} \mathrm{C}$, size of the sawdust particle from 4 to $6 \mathrm{~mm}$ and fix carbon ignition between 500 and $900{ }^{\circ} \mathrm{C}$. The values obtained for the characteristic parameters of the burning process ranged from 30 to $60\left[\mathrm{~kg} /\left(\mathrm{h} \cdot \mathrm{m}^{3}\right)\right]$ for the gravimetrical burning speed $W_{G h}$ and from 150 to $280\left[\mathrm{~kW} / \mathrm{m}^{3}\right]$ for the volumetric thermal load of the furnace $Q_{V}$. The main conclusion was that the calculus results are in good agreement with the experimental data from the pilot installations and the real-case measurements in the sawdust working boiler furnaces or pre-burning chambers. Another very important conclusion is that the process speed variation, when the furnace temperature changes, confirms the thermo-kinetic predictions, namely that the burning process speed decreases when the furnace temperature increases.
\end{abstract}

Keywords: particle, burning process, physical model, equations

\section{Introduction}

For technical applications, a physical model was developed for the burning process of the sawdust particle in fluidized bed conditions, capable to follow the main process stages and allow the comparison of the calculated thermo-physical parameters with those obtained in experimental installations.

The physical model [1 - 4] starts with the description of the thermal stages that the particle undergoes along with the temperature rise. In the case of a small particle in fluidized bed suspension conditions, the drying and volatile emitting intervals are insignificant compared with the fix carbon diffusive burning time. The explanation lies in the fact that for small particles the ratio between their lateral surface and their volume is very high, compared with bigger particles, and all the endothermic processes (such as heating, drying and volatile matter formation) are very rapid.

The nominal functioning conditions for boiler furnaces or burning pre-chambers when operating with sawdust are characterized by temperatures between 700 and $1000{ }^{\circ} \mathrm{C}$. At temperatures higher then $600{ }^{\circ} \mathrm{C}$ the fix carbon reactivity represents the main burning process characteristic and so the chemical reduction processes become predominant: $\mathrm{CO}_{2}+\mathrm{C}=2 \mathrm{CO}$.

The mass flux of oxygen reaches the particle by diffusion process and then reacts with the surface generating the oxidation process followed by the chemical reduction process. The diffusion time is the one that governs the process because the reaction between Oxygen and Carbon is very rapid and so its time becomes negligible. The thermal balance for the particle determines its heating. So, from the heat flux $Q_{A R}$ generated by the reaction, a certain amount, $Q_{C O}$, leaves with the resulting $\mathrm{CO}$ mass flow at adiabatic temperature burning conditions and another flux , $Q_{R P}$, leaves the surface by the means of surface radiation (from particle 
temperature level). Additionally, the particle receives a heat flux, $Q_{R F}$, from the furnace (environment) radiation and exchanges heat in a convective heat exchange process $Q_{C L}$ with the environment, receiving or loosing heat. The convection is physically represented by heat conduction through the boundary layer that forms around the particle due to its movement.

\section{Basic data for the fluidized bed particle burning model}

A finite element based system of equations was developed and then implemented in a specially designed software program, capable of rigorously determining the characteristic parameters for the physical stages that the particle undergoes from the initial stage to its final disappearance after the burning process.

The suspension speed of the particle in the burning chamber is a determining parameter for the thermo-physical processes. Analyzing the hydraulic equations generated by the floating conditions for the sawdust particle, it was determined that the star shaped (irregular) sawdust particle can be assimilated and described as an equivalent mass cubical particle of matter with density equal to the bulk density of the sawdust. The values obtained for the floating speed of the sawdust particle, depending on the flue gas temperature and particle equivalent side dimension, are presented in Table 1.

Table 1

Flue gas floating speed for the sawdust particle

\begin{tabular}{|c|c|c|}
\hline $\begin{array}{c}\text { side dimension } \\
\text { of the cubical particle } \\
{[\mathrm{mm}]}\end{array}$ & $\begin{array}{c}\text { furnace temperature } \\
{\left[{ }^{\circ} \mathrm{C}\right]}\end{array}$ & $\begin{array}{c}\text { floating speed } \\
{[\mathrm{m} / \mathrm{s}]}\end{array}$ \\
\hline 2 & $600-900-1200$ & $4,03-4,67-5,23$ \\
\hline 4 & $600-900-1200$ & $5,69-6,60-7,40$ \\
\hline 6 & $600-900-1200$ & $6,97-8,08-9,06$ \\
\hline
\end{tabular}

For the case of horizontally carried particles the resulting trajectory comes from the superposition of horizontal movement and vertical, gravitational dropping movement.

For different particle sizes and flue gas conditions, the Reynolds number was calculated for the particle. It was determined that the movement generates laminar flowing conditions in all the cases and so the boundary layer thickness can be determined at the particle surface with the Blasius equation:

$$
\delta=5 \cdot\left(\frac{v \cdot l}{w}\right)^{0,5} \text { or its equivalent form } \frac{\delta}{l}=\frac{5}{\mathrm{Re}^{0,5}}
$$

where $\delta$ is the boundary layer thickness, $v$ is the cinematic viscosity, $l$ is the characteristic length and $w$ is the flow speed.

Some Re numbers and the boundary layer thickness for the most common particle flotation conditions are given in Table 2.

Table 2

Boundary layer thickness for the most common particle flotation conditions

\begin{tabular}{|c|c|c|c|c|}
\hline $\begin{array}{c}\text { side dimension } \\
\text { of the cubical particle } \\
{[\mathrm{mm}]}\end{array}$ & $\begin{array}{c}\text { particle speed } \\
{[\mathrm{m} / \mathrm{s}]}\end{array}$ & $\begin{array}{c}\text { furnace } \\
\text { temperature } \\
{\left[{ }^{\circ} \mathrm{C}\right]}\end{array}$ & $\operatorname{Re}$ & $\begin{array}{c}\text { boundary layer } \\
\text { thickness } \\
{[\mathrm{mm}]}\end{array}$ \\
\hline 2 & $2-9$ & $900-1100$ & $19-69,8$ & $2,30-1,20$ \\
\hline 4 & $2-9$ & $900-1100$ & $37,9-139,6$ & $3,25-1,69$ \\
\hline 6 & $2-9$ & $900-1100$ & $56,9-209,4$ & $3,98-2,07$ \\
\hline
\end{tabular}

The Oxygen diffusion for the particle fix Carbon burning takes place through the boundary layer thickness because outside it, due to relatively high flow speeds of the flue gases, the Oxygen concentration can be considered as constant (and characteristic for the furnace gaseous 
environment) and at the particle surface, the Oxygen concentration is zero, because it is consumed by the oxidation reaction.

An important parameter for the Oxygen diffusion to the particle surface is the average distance between two particles, because if this one is much bigger than the particle boundary layer, it will not influence the process (the particles, although in a "cloud", would react as single particles in an environment with defined characteristics). Calculating the number of particles for one kilogram of material (wood) and the corresponding flue gas volume resulted from the burning of this fuel quantity, the average distances between particles (considering a uniform distribution of the particles) result as presented in Table 3 .

Table 3

Average distance between particles

\begin{tabular}{|c|c|c|c|}
\hline Flue gas tenperature $\left[{ }^{\circ} \mathrm{C}\right]$ & 900 & 1000 & 1100 \\
\hline Inter-particular distance $\delta_{p}[\mathrm{~mm}]$ & 55,3 & 56,9 & 58,3 \\
\hline Boundary layer thickness $\delta_{s l}(\mathrm{w}=9 \mathrm{~m} / \mathrm{s})[\mathrm{mm}]$ & 1,08 & 1,14 & 1,20 \\
\hline$\frac{\delta_{p}}{\delta_{s l}}$ ratio & 51 & 50 & 49 \\
\hline
\end{tabular}

It can be observed that the ratio between the average inter-particular distance and the boundary layer thickness is about 50, fact that sustains the hypothesis of no interaction (in terms of mass diffusion) between the neighboring particles during the burning process.

\section{Heat fluxes for the sawdust particle}

A heat balance schematic for the sawdust particle is presented in Figure 1.

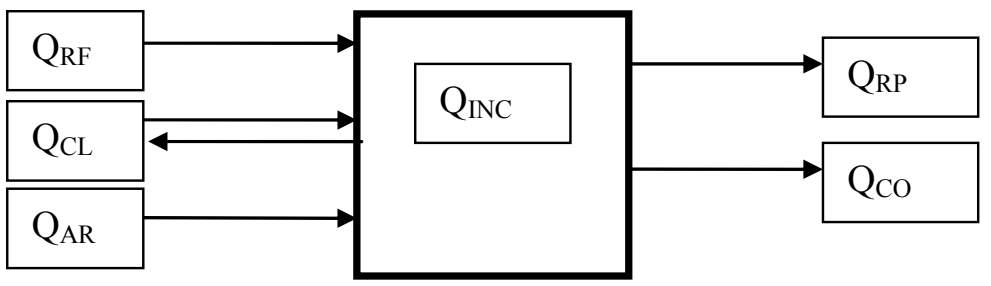

Fig. 1 - Heat fluxes for the sawdust particle

where:

- $Q_{I N C}$ is the available heat for heating the particle;

- $Q_{A R}$ is the heat generated by the burning process of the Carbon to Carbon monoxide;

- $Q_{C O}$ is the heat that leaves the particle with the CO flue gases at burning temperature in adiabatical conditions;

- $Q_{R F}$ is the radiative heat emitted by the furnace gaseous environment;

- $Q_{R P}$ is the radiative heat emitted by the particle surface at the particle temperature;

- $Q_{C L}$ is the convective heat exchanged by the particle with the flue gas environment.

The heat quantities from the heat balance were determined as following:

- $Q_{A R}$, for a time lap $\Delta \tau$ sufficiently short so that the process parameters would not be affected by the particle temperature variation, can be calculated considering the following process characteristics and boundary conditions:

- the calorific power of fix carbon burning to carbon monoxide $H_{C A R B}$ has the value of $10308 \mathrm{~kJ} / \mathrm{kg}$; 
- the thickness of diffusion layer $\delta_{g}$ is the same with the boundary layer thickness $\delta_{s l}$ defined as a function of relative speed $w_{\text {rel }}$ of the particle in the flue gas environment;

- the average boundary layer temperature $T_{\text {lim }}$ is considered as the mean value between the furnace temperature $T_{f}$ and the initial particle temperature at the specific moment $T_{l}$;

- the calculus of Oxygen partial pressure in the gaseous environment of the furnace $P_{\mathrm{O} 2}$ is dependent on the air excess in the overall burning process; the initial Oxygen concentration $O_{2 I N I}$ corresponds to the Oxygen concentration after the volatile burning process and the final Oxygen concentration $O_{2 F I N}$ corresponds to the final air excess; the partial pressure is determined in average conditions:

$$
O_{2 M E D}=\frac{O_{2 I N I}+O_{2 F I N}}{2} ; P_{O 2}=98066 \cdot \frac{O_{2 M E D}}{100}[\mathrm{~Pa}]
$$

- $\quad$ at the particle surface the partial pressure of the Oxygen is zero;

The diffusion coefficient for the oxygen $D_{O 2}$ is determined as a function of the boundary layer mean temperature $T_{\text {lim }}\left[{ }^{\circ} \mathrm{C}\right]$ :

$$
D_{O 2}=0,203 \cdot 10^{4} \cdot\left(\frac{T_{\text {lim }}+273}{273}\right)^{1.81}
$$

The reactive surface is considered to be the whole lateral surface of the particle and so, the specific mass flux of the oxygen $J_{O 2}$, can be calculated with the mass transfer equation:

$$
J_{O 2}=D_{O 2} \cdot \frac{M_{O 2} \cdot P_{O 2}}{R_{G} \cdot\left(T_{\text {lim }}+273\right) \cdot \delta_{s l}}\left[\frac{\mathrm{kg}}{\mathrm{m}^{2} \cdot \mathrm{s}}\right]
$$

where $R_{G}$ is the universal constant of the gases and $M_{O 2}$ is the molar mass of the oxygen.

The Carbon mass in reaction is in the ratio 12/16 with the Oxygen mass and so the Carbon mass flux $M_{C}$ consumed on the particle surface $S_{p}$ is:

$$
M_{C}=\frac{12}{16} \cdot J_{O 2} \cdot S_{p}\left[\frac{\mathrm{kg}}{\mathrm{s}}\right]
$$

In the time lap $\Delta \tau$ a variation in the carbon mass of the particle $\Delta M_{C}$ will be considered:

$$
\Delta M_{C}=M_{C} \cdot \Delta \tau[\mathrm{kg}] \quad \text { and therefore } \quad M A S_{\text {fin }}=M A S_{\text {in }}-\Delta M_{C} \quad[\mathrm{~kg}]
$$

For an average composition of the sawdust particle of $15 \%$ humidity and $45 \%$ volatile matter, the initial fix carbon mass is averaging $40 \%$ because the ash content of wood is less than $1 \%$ and can be neglected. The heat generated by the fix Carbon burning process will be:

$$
Q_{A R}=\Delta M_{C} \cdot H_{C A R B} \cdot 1000[\mathrm{~J}]
$$

$Q_{C O}$ depends on the quantity of CO flue gases and their adiabatical burning temperature. The quantity of $\mathrm{CO}$ produced by the burning of $\Delta M_{C}$ fix Carbon mass is given by the molar mass equation: $12 \mathrm{~kg} \mathrm{C} \rightarrow 20 \mathrm{~kg} \mathrm{CO}$. So the generated $\mathrm{CO}$ flue gases mass for the considered time interval will be: $\Delta M_{C O}=\Delta M_{C} \cdot 20 / 12[\mathrm{~kg}]$.

The Carbon monoxide is formed at particle temperature $T_{1}$ and it is evacuated in the furnace environment at its adiabatical burning temperature $T_{t}$ corresponding to the burning reaction $\mathrm{C} \rightarrow$ $\mathrm{CO}$. The heat quantity consumed for the heating process (of the CO mass) will be:

$$
Q_{A R}=\Delta M_{C O} \cdot \overline{c_{p C O}} \cdot\left(T_{t}-T_{1}\right)[\mathrm{J}]
$$

The heat flux transmitted to the particle by the furnace environment can be calculated considering that in a high intensity burning process of the particles cloud the radiation emission 
coefficient of the gaseous environment reaches values around $\varepsilon_{g}=0,9$ and the radiation absorption coefficient of the particle can be approximated with $\varepsilon_{p}=1$. It results for the time interval $\Delta \tau$ a heat quantity $Q_{R F}$ radiated by the furnace environment (to the particle's surface) :

$$
Q_{R F}=C_{0} \cdot \varepsilon_{g} \cdot \varepsilon_{p} \cdot\left(T_{f}+273\right)^{4} \cdot S_{p} \cdot \Delta \tau[\mathrm{J}]
$$

where $C_{0}$ is the Stephan-Boltzmann radiation invariant.

The heat transmitted by the particle's surface to the furnace environment $Q_{R P}$ can be calculated in similar conditions as the received heat $Q_{R F}$. It results for the $\Delta \tau$ time interval a heat quantity radiated by the particle surface (to the furnace) :

$$
Q_{R P}=C_{0} \cdot \varepsilon_{g} \cdot \varepsilon_{p} \cdot\left(T_{p}+273\right)^{4} \cdot S_{p} \cdot \Delta \tau[\mathrm{J}]
$$

Finally, the heat exchanged by the particle by convection $Q_{C L}$ (considered positive if received by the particle) is due to the particle movement in floating conditions in the furnace's flue gas environment. The convective heat transfer comes over the radiative heat transfer of the particle. Because the boundary layer thickness was priory determined it is simpler to replace the convective heat transfer calculus with the conductive heat transfer calculus through the boundary layer. It results:

$$
Q_{C L}=S_{p} \cdot \frac{\lambda_{g}}{\delta_{s l}} \cdot\left(T_{f}-T_{\lim }\right) \cdot \Delta \tau[\mathrm{J}]
$$

From the heat balance of the particle, as presented in Figure 1, the heat resource for the particle temperature rise $Q_{I N C}$ can be calculated as:

$$
Q_{I N C}=Q_{A R}-Q_{C O}+Q_{R F}-Q_{R P}+Q_{C L} \quad[\mathrm{~J}]
$$

This heat quantity determines the rise of the particle temperature and, because its dimensions, the temperature can be considered uniform in the whole volume. The resulting temperature rise is:

$$
\Delta_{T}=\frac{Q_{I N C}}{M A S_{p} \cdot c_{p a r}}[\mathrm{~K}]
$$

The temperature of the particle at the end of the time interval will be the initial temperature of the particle plus the temperature rise of the particle for the given interval. The resulting temperature represents the initial temperature for the particle in its evolution for the next time interval. The mass of the particle also changes after each interval, diminishing with the fix Carbon quantity consumed in each calculus time lap (6). Because the mass of the particle changes, the geometry of the particle also changes, and considering that the cubic form is characteristic for the particle geometry in any moment of the burning process, a new side dimension results after each step, given by the relations:

$$
L A T_{\text {fin }}=V_{p}^{\frac{1}{3}} \text { where } V_{p}=\frac{M A S_{f i n}}{\rho_{p}}
$$

The calculus ends when the particle mass reaches 0 , namely when the entire carbon particle is consumed.

\section{Temperature time dependent evolution for the particle burning process}

A calculus program for the burning process of the sawdust particle in flue gas suspension conditions was developed by the authors and the computing results were compared with the experimental data in order to validate the calculus. From the beginning it is important to state that the calculus and the experimental results were in good agreement, leading to the validation of the program. The experiments necessary to validate the program were performed on a pilot testing installation and on real scale furnace installations, available in the author's university Thermal Appliances Laboratory. 
The program was set for sawdust modeling conditions and the time increment was set to $1 / 100$ seconds. Each parameter variation (temperatures, masses etc.) was verified to be less than $1 \%$ of its initial value. In this way, the overall error made by incremental calculus of the heat fluxes is less then $1 \%$ compared to the (time) continuous heat fluxes calculus.

For a typical case of fluidized bed sawdust particle burning process the calculus results for the particle temperature are presented in Figure 2.

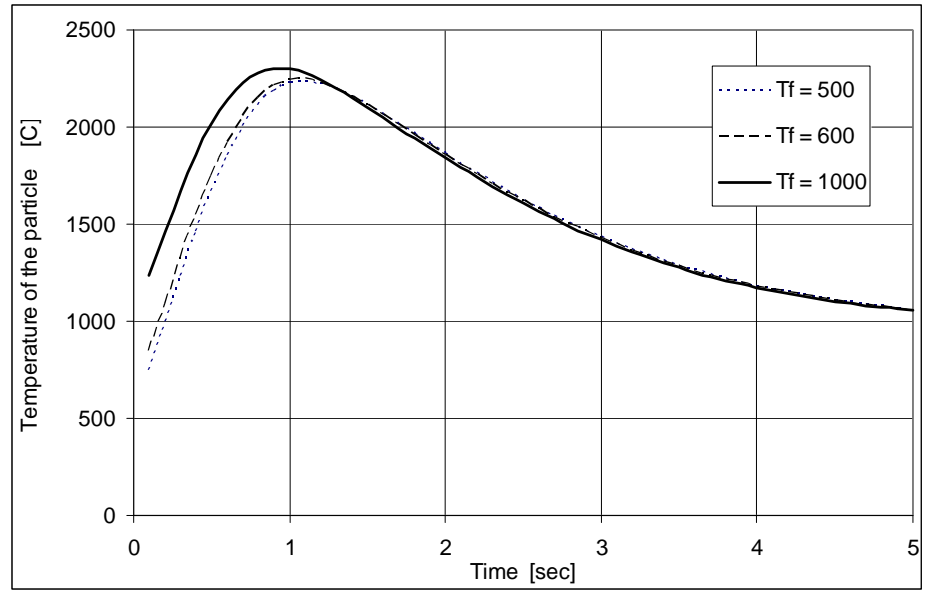

Fig. 2 - Time dependent particle temperature for different furnace temperature values

From the graph presented in Figure 2 the following conclusions can be drawn:

The particle temperature raises from the initial equilibrium (with the furnace environment) temperature to $2200-2300{ }^{\circ} \mathrm{C}$ as a result of the intense heat flux generation by internal reactions. For a quite large domain of variation of the initial temperature the maximum temperature reached by the particle is approximately the same. The fact proves that whatever considered being the starting temperature for the fix Carbon burning process in the domain ranging from 500 to $1000{ }^{\circ} \mathrm{C}$, the final process temperature is approximately the same.

After the intense processes domain, the temperature of the particle decreases because its volume is diminishing, resulting in less reacting mass for a certain heat loss. The fact is explained by the reduction of the ratio between the particle volume Vp and the particle lateral surface Sp.

In the domain of temperature decreasing, whatever the furnace temperature, the decreasing curves are quite the same in aspect and values.

The burning process ends by the complete consumption of the particle at a temperature level averaging $1100^{\circ} \mathrm{C}$.

\section{Heat fluxes time dependent evolution for the particle burning process}

Observing the heat fluxes evolution in respect of the time for the burning particle is very important because it gives consistency to the conclusions drawn from the particle temperature evolution analysis.

The heat flux generated by the fix Carbon burning process and the heat flux consumed by the produced $\mathrm{CO}$ flue gases in their heating process are represented in Figure 3.

In the first second of the burning process, the generated heat flux is important due to the large reaction surface of the particle, its diameter varying insensibly from its initial value. After the initial period, because the particle volume significantly decreases along with the fix Carbon mass consumption, the lateral surface of the particle consequently decreases. Because the lateral surface is the reaction surface (where the Oxygen gets by diffusion process), this will generate the decrease of the Carbon mass consumption ratio and therefore the important decrease of the heat flux generated by fix carbon diffusive burning process. After 3 seconds, the particle is consumed in a 95 $\%$ proportion and the processes tend asymptotically to complete particle consumption. 

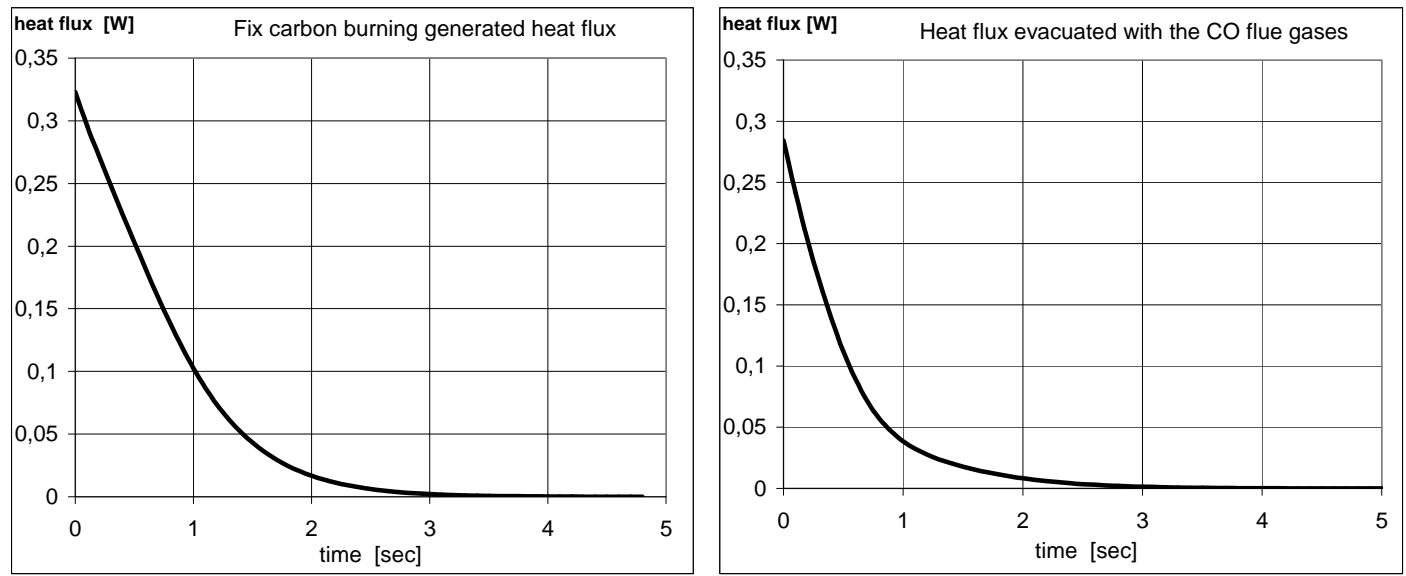

Fig. 3 - Evolution of the heat fluxes generated by Carbon reaction and consumed by CO flue gas heating

Because all the kinetic processes are not in fact ending but asymptotically tending to zero, however, technically speaking, the process can be considered as finished if the particle mass undergoes $1 / 10^{6}$ of its initial value. With this condition, the total burning time is averaging 5 seconds.

The main heat loss flux is the one with the hot $\mathrm{CO}$ flue gases. Its variation respects the shape of the graphic for the generated heat flux (by Carbon reaction) because the $\mathrm{CO}$ debit is directly dependent of the Carbon mass consumption (by burning process). As previously shown, it is considered that the $\mathrm{CO}$ flue gases generate a heat loss due to the enthalpy difference between formation temperature (adiabatic $\mathrm{C}$ to $\mathrm{CO}$ burning temperature) and furnace flue gas environment temperature.

The resultant of the two radiative heat exchange fluxes (namely the radiation flux generated by the particle and the radiation flux received by the particle) combined with the convection flux at the particle surface, is presented in Figure 4 along with the resulting available heat flux for particle heating process, obtained from the total heat balance.
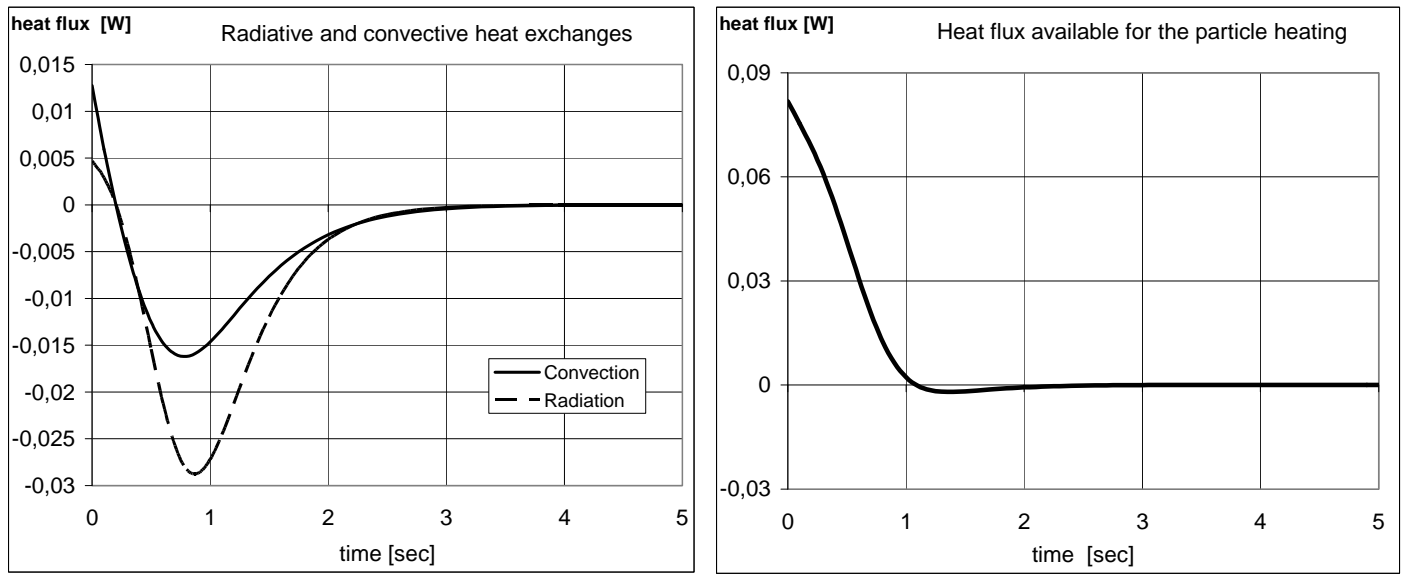

Fig. 4 - Surface heat exchange resultant flux and the flux available for particle heating

\section{Considerations about fluidized bed sawdust particles burning process stability}

As shown by the graphical representations of the heat fluxes, the thermal processes intensity is very high at the beginning of the burning process, generating important and rapid temperature variations. After a while, the processes intensity rapidly decreases and tends asymptotically to stabilization values. Considering the technical definition of process ending as given before, the burning process time for different sizes of sawdust particles are presented in Table 4.

A very important conclusion can be drawn from Table 4, namely that in the fluidized bed burning process, the burning speed for sawdust particles is decreasing along with the furnace temperature rise. 
The fact may seem strange from the point of view of chemical reaction kinetics, being known the fact that chemical reactions speeds are exponentially increasing with the temperature rise (law of Arrhenius). But nevertheless, the second principle of thermodynamics states that a physical process is stable when, as a result of one parameter variation, another parameter changes and counterbalance the variation tendency generated by the fist parameter variation. So, if the temperature rises in a chemical reaction, the result is the shifting of the reaction to bigger energetical consumptions, in order to compensate the temperature rise. The process is stable if it reaches a new equilibrium state.

Burning process time for sawdust particles

Table 4

In technical applications it was determined that a furnace load increase (that manifests as a temperature rise for the furnace gaseous environment) does not result in process instability, the system gaining a new equilibrium state. The explanation for this behavior states in the fact that at the average (overall) rise of the gaseous environment temperature, another definitive parameter counterbalances the effect by generating a temperature drop tendency in the system. The only definitive parameter capable to be the counter effect of the temperature rise is the burning speed of the particle.

Starting from those experimental observations and theoretical statements, the model for the burning process of the particle in fluidized bed conditions was used to determine the burning speed and mainly to demonstrate its decreasing evolution with the furnace gaseous environment temperature rise.

A more accurate and technical description of the particle burning speed can be offered by the means of other two characteristic parameters, specific for furnaces, and mainly depending on the particle dimensions and furnace average temperature: the gravimetrical burning speed and the volumetric thermal load of the furnace. The two parameters can be calculated using a simple algorithm presented in Table 5.

Table 5

Calculus algorithm for the gravimetrical burning speed and furnace volumetric load

\begin{tabular}{|l|l|}
\hline \multicolumn{1}{|c|}{$\begin{array}{c}\text { furnace temperature }=t_{f}\left[{ }^{\circ} \mathrm{C}\right] \\
\text { side dimension of the particle }=d[\mathrm{~m}]\end{array}$} \\
\hline Normal flue gas volume for 1 kg of combustible (wood) & $V_{g N}=V_{g 0}+(\alpha-1) \cdot V_{0} \quad\left[\mathrm{~m}^{3} / \mathrm{kg}\right]$ \\
\hline Real flue gas volume for 1 kg of combustible & $V_{g}=V_{g N} \cdot\left(273+t_{f}\right) / 273 \quad\left[\mathrm{~m}^{3} / \mathrm{kg}\right]$ \\
\hline One particle mass & $m_{p}=d^{3} \cdot \rho \quad[\mathrm{kg}]$ \\
\hline Number of particles per kilogram & $N=1 / m_{p}$ \\
\hline Furnace volume corresponding to one particle & $V_{I}=V_{g} / N \quad\left[\mathrm{~m}^{3}\right]$ \\
\hline Number of particles per furnace volume unit & $N_{V}=1 / V_{l} \quad\left[\left(\mathrm{~m}^{3}\right)^{-1}\right]$ \\
\hline Gravimetric load for the furnace volume unit & $G_{V}=N_{V} \cdot m_{p} \quad\left[\mathrm{~kg} / \mathrm{m}^{3}\right]$ \\
\hline Particle burning time (see Table 4) & $\tau_{p} \quad[\mathrm{~s}]$ \\
\hline Gravimetrical burning speed $W_{G}$ & $W_{G}=G_{V} / \tau_{p} \quad\left[\mathrm{~kg} /\left(\mathrm{s} \cdot \mathrm{m}^{3}\right)\right]$ \\
\hline Hourly expressed gravimetric burning speed $W_{G h}$ & $W_{G h}=W_{G} \cdot 3600$ \\
\hline Volumetric thermal load of the furnace $Q_{V}$ & $Q_{V}=W_{G} \cdot H_{i} \quad\left[\mathrm{~kW} / \mathrm{m}^{3}\right]$ \\
\hline
\end{tabular}

In Figure 5 and Figure 6 the graphical representations for the two furnace characteristics are presented, the gravimetrical burning speed $W_{G}$ and the volumetric thermal load of the furnace 
$Q_{V}$, in respect of the cubical particle side dimension (varying from 2 to $8 \mathrm{~mm}$ ), in three furnace average temperature situations $\left(700,800\right.$ and $\left.900{ }^{\circ} \mathrm{C}\right)$.

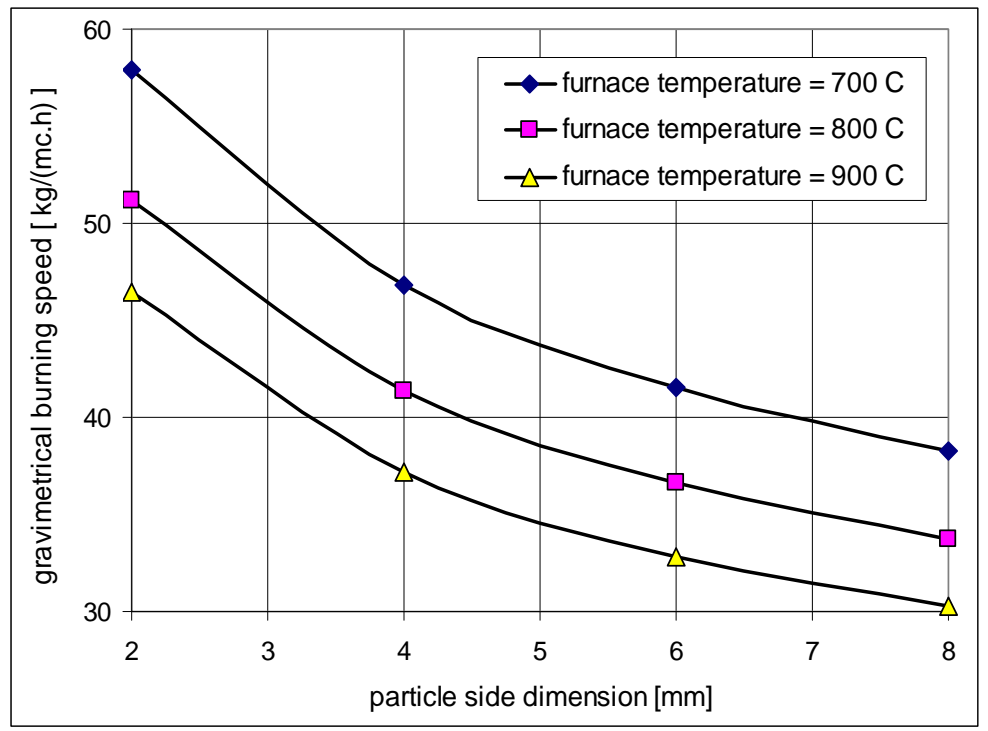

Fig. 5 - The gravimetrical burning speed WG

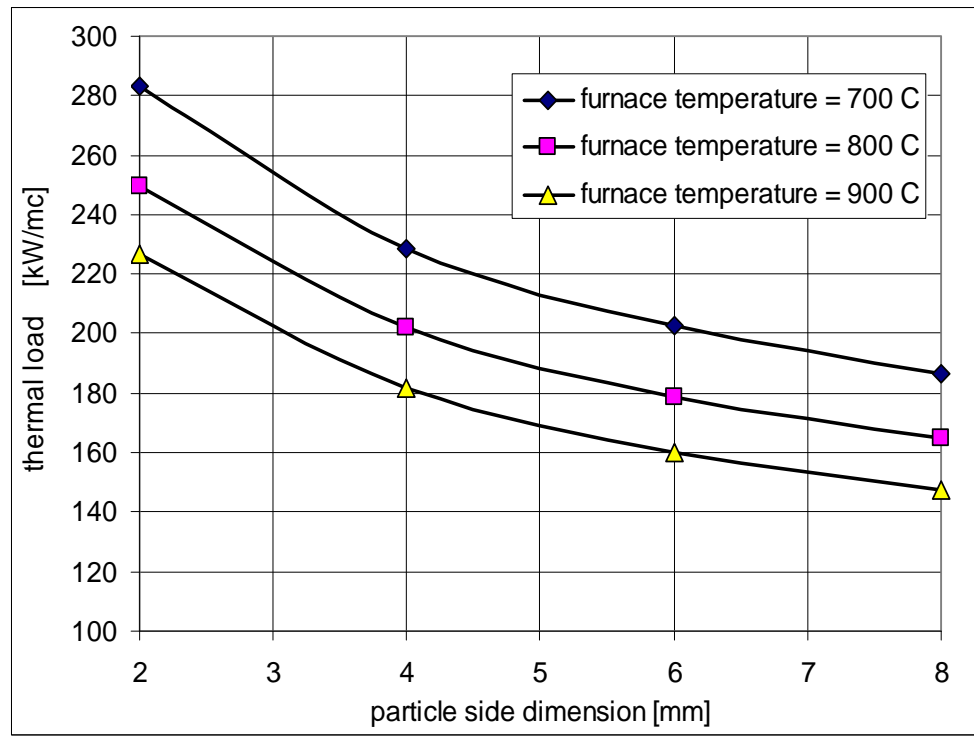

Fig. 6 - The volumetric thermal load of the furnace QV

From the two diagrams (Figure 5 and Figure 6) it clearly results that the burning speed in the furnace decreases with the temperature rise, as it was previously estimated by applying the stability conditions to the fluidized bed furnace functioning conditions.

Also, it is important to mention that the known fact that a smaller fragmentation of the infeed solid fuel leads to bigger thermal loads (due to the increase of the reactive surface of the mass unit of fuel) is confirmed by the calculated loads for the furnace (as presented in Figure 6).

\section{Conclusions}

The burning process stability, for the sawdust particles in fluidized bed furnace conditions, is generated by the decrease of the particle burning speed when the furnace temperature rises.

For the cubical sawdust particles with the side dimensions between 2 and $8 \mathrm{~mm}$, the distance between particles exceeds 50 times the particle characteristic size and therefore, in the burning process model, the boundary layer of each particle can be considered independent from other particles boundary layers. 
The steady state functioning of the fluidized bed furnace when operating with sawdust is characterized by average temperatures between 700 and $900{ }^{\circ} \mathrm{C}$. At those temperature levels and considering a relative movement for the particle given by the flotation conditions, the heating, drying and volatile emission phases take a short time compared with the total particle burning time. The determining time is the fix Carbon diffusive burning time, after volatile matter elimination. The fix Carbon burning model developed and presented in the paper was confirmed by experimental determinations on pilot installation and real-scale furnaces.

The results obtained from the model targeted to determine the particle burning speed variation linked to furnace temperature variation. For the input parameter (particle dimensions and furnace temperatures) variation in the domains previously stated, the values obtained for the gravimetrical burning speed $W_{G}$ ranged from 30 to $60\left[\mathrm{~kg} /\left(\mathrm{h} \cdot \mathrm{m}^{3}\right)\right]$ and those for the volumetric thermal load of the furnace $Q_{V}$ ranged from 150 to $280\left[\mathrm{~kW} / \mathrm{m}^{3}\right]$.

\section{References}

[1]. Grotkjaer, T., Dam-Johanses, K. et al.(2003). An experimental study of biomass ignition, Fuel Journal, vol.82, (pp $825-833)$.

[2]. Ballester, J., Barroso, J., et al. (2005). Comparative study of semi-industrial-scale flames of pulverized coals and biomass, Combustion and Flame, vol.141, (pp. 204-215).

[3]. Antonescu, N., Stanescu, P.D., Antonescu, N.N. (2002). Burning processes - theoretical and experimental bases, published by Matrix-Rom Bucharest.

[4]. Winter, F., Prah, M.E., Hofbauer, H. (1997). Temperatures in a fuel particle burning in a fluidized bed: The effect of drying, devolatilization, and char combustion, Combustion and Flame, vol.108, (pp.302 - 314). 